This is the peer reviewed version of the following article: 'Emotional labor and professional practice in sports medicine and science', which has been published in final form at https://doi.org/10.1111/sms.12941. This article may be used for non-commercial purposes in accordance with Wiley Terms and Conditions for Self-Archiving.

24 This research received no specific grant from any funding agency in the public, commercial, or not-for-profit sectors. 
Abstract

The aim of the present study was to explore how sport medicine and science practitioners manage their emotions through emotional labor when engaging in professional practice in elite sport. To address the research aim a semi-structured interview design was adopted. Specifically, eighteen professional sport medicine and science staff provided interviews. The sample comprised sport and exercise psychologists $(n=6)$, strength and conditioning coaches $(n=5)$, physiotherapists $(n=5)$, one sports doctor and one generic sport scientist. Following a process of thematic analysis, the results were organized into the following overarching themes: (a) factors influencing emotional labor enactment, (b) emotional labor enactment and, (c) professional and personal outcomes. The findings provide a novel contribution to understanding the professional demands faced by practitioners, and are discussed in relation to the development of professional competencies and the welfare and performance of sport medics and scientists.

Keywords: emotion, emotional displays, emotion regulation, well-being, professions,

40 professional development 


\section{Emotional labor and professional practice in sports medicine and science}

The pursuit of athletic excellence in high performance sport is increasingly informed by innovative medical, scientific, and technological advances driven by the expertise of sports medics and scientists (SMSs) (Wagstaff, Gilmore \& Thelwell, 2015), who are relied upon to improve and optimize athlete performance. The persistent demands for performance success, the obligation to interact with various stakeholders, the need to work as part of a multidisciplinary sports medicine and science team, and the emotionality of the elite performance context has arguably increased SMSs necessity to perform emotional labor. The term emotional labor has been recently defined as, "emotion regulation performed in response to job-based emotional requirements in order to produce emotion toward - and to evoke emotion from another person to achieve organizational goals" (Grandey, Diefendorff \& Rupp, 2013, p. 18; see also Hochschild, 1983). Previous research has demonstrated how individuals are required to enact emotional labor as part of their role in sport, including athletes (e.g., Tamminen \& Crocker, 2013), coaches (e.g., Nelson et al, 2013), personal trainers (e.g., George, 2008), and performance directors (e.g., Wagstaff, Fletcher \& Hanton, 2012). Nevertheless, to date there has been no research into the role of emotional labor in SMS professionals.

\section{Professional practice in sport}

Given the salient role that SMS play in sport organizations (Reid, Stewart \& Thorne, 2004), the aim of this study was to investigate the extent to which SMSs' are required to engage in emotional labor and to examine the implications of our findings here for professional practice in the elite sport environment. Within this study, the term "professional practice" refers to the development of students, trainees, and qualified practitioners in the educational or work context in accordance with training guidelines set down by relevant professional or accrediting bodies (e.g., Anderson, Knowles \& Gilbourne, 2004). Indeed, although professional practice guidelines are typically characterized by theoretical knowledge and practical skills that are underpinned by evidence based practice to be deemed "competent" in each professional domain, recent research 
has highlighted the need to devote attention to the interpersonal and relational skills required for SMS's to be effective in their role (Tod, Marchant \& Andersen, 2007). Specifically, Tod et al. (2007) found displays of empathy were perceived as critical to effective practice when interacting with athletes. Moreover, practitioners have reported difficulties when attempting to transfer theoretical knowledge to emotion-laden situations in applied practice across one-to-one and team settings, and when travelling to unfamiliar locations (see Tonn \& Harmison, 2004). Similarly, practice reflections of physiotherapists portray the range of positive and negative emotions felt, concealed, and expressed with clients as part of their professional demands (Foster \& Sayers, 2012). In the SMS domain, the salience of organizational change such as a change in management have been reported to increase emotional labor requirements of SMS's which might lead to higher incidence of burnout (Wagstaff et al., 2015). Therefore, emotional labor might have far reaching positive consequences for professional practice when working with stakeholders in sport, which previous findings have yet to detail.

\section{Emotional labor in sport}

Sociological studies exploring sport-specific cultural norms have provided insight into the emotional display requirements athletes and coaches face (Gallmeier, 1987; Galvan \& Ward, 1998). For example, Gallmeier (1987) found emotional display requirements and emotional expressiveness changed before, during, and after professional hockey games for the athletes and head coach. To elaborate, Gallmeier observed that the head coach and players were expected to display a calm and business-like demeanor before matches. In contrast, during the game the head coach and players were expected to display intense, positive emotions to maximize team performance. Interestingly, there is also evidence from interpersonal perceptions literature to indicate the value of emotional expressiveness on sport performance. Manley, Greenlees, Thelwell, Filby, and Smith (2008) found facial expressions, body language and gestures to be important cues for athletes when forming impressions of their coach. These findings indicate that when coaches' express emotions in adherence to emotional display 
requirements during competitive matches, this is associated with desired effects such as positive psychological states and match-winning performance. Further, an interview study examining stress in the coach-athlete relationship found athletes could perceive when their coaches were under strain through facial expressions and verbal tone. This implies that coaches need to mask their negative emotions through emotional labor, and the effort associated with displaying desired emotions to athletes might lead to the detriment of coaches' general well-being and effectiveness (Thelwell, Wagstaff, Rayner, Chapman \& Barker, 2016). Subsequent work has extended these findings to the sport and physical activity domain (Tamminen \& Bennett, 2017). Conceptualizing emotional labor as a psychosocial and performative process, Tamminen et al (2017) found the socio-cultural contexts that sports athletes, coaches, and trainers operate in dictate the degree to which emotional expressiveness is appropriate. Such elements of professional practice could be critically reflected on and developed as interpersonal skills by trainees and practitioner SMSs.

In recent years, emotional labor has become a variable of interest to coaching science scholars (see, e.g., Larner, Wagstaff, Thelwell, Corbett, 2017; Lee \& Chelladurai, 2016; Lee, Chelladurai \& Kim, 2015; Nelson et al., 2013). Revealing the emotionality of professional practice in football coaching, Nelson et al. (2013) illustrated how a coach expressed and concealed his true emotions to achieve desired ends. Despite feelings of inauthenticity, the need to exude desirable emotions in front of athletes to drive performance was prioritized. A quantitative program of research by Lee and colleagues $(2015 ; 2016)$ found surface acting predicted increased psychological costs such as emotional exhaustion, emotional dissonance, and feelings inauthenticity. This implies that the increased emotional effort needed to surface act (i.e., suppressing felt emotions) can lead to negative mental health outcomes in coaches. In a recent multilevel questionnaire study examining emotional labor in sport organizations, athletes and coaches who demonstrated high levels of surface acting were more likely to perceive the frequency of organizational stressors encountered as negative, and therefore suffer burnout 
(Larner et al., 2017). These findings demonstrate links between emotional labor and both positive or negative personal and professional outcomes for sports coaches.

Overall, the research above provides a valuable insight into the potential salience of emotional labor in sport. Nevertheless, no research has explored the emotional labor process in SMS professions. Such a dearth seems curious given the emotive nature of elite sport and pivotal role of support staff for the performance and wellbeing of athletes and teams in elite sport. What remains unclear is the nature of emotional display requirements, emotion regulation, and emotion expressiveness for SMSs in elite sport, and the influence of such demands on practitioners. Therefore, this study presents a novel investigation of emotional labor in SMS professionals. The findings of such explorations have the potential to contextualize the work of SMS professionals in elite sport, and potentially inform education and training, professional guidelines, codes of conduct, and governance regarding how practitioners are expected to act when working in elite sport. To this end, the following research questions guided the study: (a) to what extent do SMS professionals feel they enact emotional labor? (b) what factors influence the enactment of emotional labor? (c) in what ways do SMS practitioners enact emotional labor with athletes and members of multi-disciplinary teams, and (d) how does emotional labor impact professional practice in SMSs?

\section{Method}

\section{Design}

This investigation was underpinned by philosophical assumptions of ontological relativism (i.e., reality is multiple, created, and mind dependent) and epistemological interpretivism (i.e., knowledge is subjective and shaped by lived experience). Specifically, a qualitative design was implemented to address the research questions. Semi-structured interviews were chosen to address the research questions to allow adequate collection of information about the topic of interest while giving participants a degree of flexibility to expand on their thoughts, feelings and experiences regarding pertinent issues (Sparkes \& Smith, 2014). 
The authors engaged in abductive reasoning, which involved "dialectical movement between everyday meanings and theoretical explanations" (Ryba, Haapanen, Mosek \& Ng, 2012, p. 85), which were then applied to the data. Such a procedure was followed because the aims of the study were to establish whether and how emotional labor was constituted in SMS (deductive) and to understand the impact of emotional labor in professional practice (inductive).

\section{Participants}

Participants were recruited via purposive snowball sampling. The sampling criteria included participants who were fully qualified and professionally accredited practitioners, and were actively practicing in the United Kingdom at national sport level. Therefore, research participants were accredited by one or more of the following national governing or regulatory bodies; the General Medical Council (GMC), the Health Care and Professions Council (HCPC), the British Association of Sport and Exercise Sciences (BASES), the British Psychological Society (BPS), the Chartered Society for Physiotherapists (CSP), or the United Kingdom Strength and Conditioning Association (UKSCA).

The sample comprised eighteen active sports medicine and science practitioners ( 15 male, 3 female) including six sport and exercise psychologists, five strength and conditioning coaches, five physiotherapists, one sports doctor, and one generic sports scientist. The decision to include various SMS roles in this study was guided by Larner et al (2017) to achieve a varied sample to provide insight into emotional phenomena. The hard-to-reach nature of the target population, the lack of sampling frame, and the gender imbalance of SMSs in elite sport (e.g., Bekker \& Blake, 2016) resulted in a sample that is predominantly male. All participants, either in the past or at present, practiced within a range of individual (e.g., golf, swimming, triathlon) and team based (e.g., football, rugby, cricket) national and international level sports in the United Kingdom. Demographic information such as names and locations were edited and pseudonyms used to depersonalize participant quotations. The number of years of experience for each participant is also displayed in ranges to protect anonymity (see Table 1). 


\section{Data collection}

Following institutional ethical approval, interviewees were recruited through initial email contact with SMS employed by national sports institutes or listed on publicly accessible registers (e.g. Football Medicine Register). The email included a participant information sheet detailing their ethical rights and what their involvement in the study would include, and an informed consent form. Those practitioners who indicated an interest were contacted to arrange an interview. All participants provided written informed consent prior to the interview. The interviews lasted on average for 63 minutes and were conducted with each participant on a oneto-one basis. Interviews were conducted by the first author either face-to-face $(n=8$, mean duration 64 minutes), online using Skype video calls ( $n=6$, mean duration 69 minutes), or over the telephone ( $n=4$, mean duration 60 minutes). Seventeen interviews were audio recorded and handwritten notes were made concurrently. One interviewee declined to be audio recorded but consented to the use of their data from the researcher's handwritten notes.

Interview guide. An interview guide with three sections was developed; the interview structure and questions drew on the research questions and the trifocal theory of emotional labor (Grandey \& Gabriel, 2015), addressing emotional display requirements, emotion regulation, and emotion performance aspects of emotional labor. Open ended questions were used and pertinent avenues of conversation deemed important to the research questions were probed. The interview schedule is available on request from the first author. One pilot interview was conducted with a sport and exercise scientist and the data is included in this paper.

\section{Data analysis}

In keeping with the aims of the study and its interpretivist epistemology, the data were analyzed through interpretive thematic analysis (Braun, Clarke \& Weate, 2016). This analysis method was chosen because of its potential to provide insight into people's experiences, as well as any aligned factors or processes that might influence a given phenomenon (Braun et al., 2016). The research team engaged in the six-step analytical process outlined by Braun et al. 
(2016). First, the data were transcribed verbatim, which produced 516 pages of double-spaced typed text. The first and second authors then read and re-read the transcripts to familiarize themselves with the content. Second, the data were coded in a systematic manner using general labels across the dataset. Memos and codes were handwritten on the transcripts and transferred to a master codebook that included 70 codes. Throughout this process, the first two authors engaged in analytical conversations, looking for concepts that contributed to the research questions. Third, and incorporating stages three to five of the analysis, the codes were developed and organized into themes. For example, codes relating to self-awareness, reflection, and flexibility in emotional labor approach were amalgamated in to the experience theme.

Overarching themes representing the subthemes and the interconnectedness of each theme were developed. The themes were reviewed and refined by the research team by creating and progressively altering a thematic map, as well as renaming and defining the themes. The final step of writing up was aided by further analysis in response to peer review comments of an earlier version of the paper, and were integral to the creative analytical process.

Braun and Clarke (2006) proposed a checklist to promote robust research procedures from start to finish. Following this approach, the research team maintained an audit trail of the transcripts, coding, and analysis phases of the analysis (i.e., paper trail and member checking of the research materials). In alignment with our ontological and epistemological position we also sought to engage with the interpretative potential of the qualitative approach when making sense of the data (Cassidy, 2016). We strove to be reflexive and interactive with one another throughout the analysis phase, attempting to acknowledge and explore the complex nature of elite sport organizations, and the practitioners that operate within them.

As a qualitative study, universally applied criteria are inappropriate for its evaluation (see Tracy, 2010) and the method we deployed here was guided by Smith and McGannon (2017) to enhance the substantive contribution of the topic, the emotional and intellectual impact of the topic, and the coherence with which the research questions, method, and results 
create a meaningful picture. This involved maintenance of an audit trail incorporating both data collection and theoretical matters and aimed for SMS practitioner and academic resonance (i.e., how the research relates to readers through naturalistic generalization; Smith et al., 2017; Burke, 2016).

\section{Results}

The results are presented under three overarching themes that elucidate emotional labor and professional practice in SMS: (a) factors influencing emotional labor enactment, (b) emotional labor enactment, and (c) professional and personal outcomes. The overarching themes are presented separately for the purposes of organizing the data, yet the themes are not mutually exclusive. Indeed, and as shown in Figure 1, our interpretation of these data are that emotional labor and professional practice in SMS is a social, intersubjective and reflective process whereby SMSs become increasingly aware of the influencing factors and outcomes of their emotional labor enactment through reflection.

\section{Factors influencing emotional labor enactment}

The participants spoke at length of personal and situational factors that influenced how they enacted emotional labor. The data suggest a range of contextually specific situations and cultural or organizational expectations as well as personal characteristics that prompted this behavior and the extent to which learning through reflection on past experiences of emotional labor also influenced their subsequent reactions to emotional encounters.

Context. An influential factor affecting emotional labor enactment was the context or situations practitioners found themselves in with stakeholders (i.e., athletes, coaches, backroom staff) and the specific context of their sport.

Emotional transactions. The participants described array of emotionally laden contextual situations their work involved, from total elation, "When we won the Premiership, I remember standing in Twickenham stadium looking at a group of men with tears streaming down their face" (Lilly, sport and exercise psychologist), to hopeless despair, "They had lost a 
player, a team mate, he committed suicide relatively recently" (Rory, sport and exercise psychologist). On occasions, emotional contexts were complex and ambiguous. For example, Jonny, a sport and exercise psychologist, recalled a distressing encounter with a professional cricketer who broke down after receiving a prestigious award from his club due to the emotional trauma of his wife's post-natal condition:

He came onto the balcony and literally a minute later he sat down next to me and was in floods of tears. His wife had just had a baby and she had post-natal depression and was suicidal. You can see people looking at this individual being applauded and at that point, it was the last thing that was important to him. Listening to somebody, supporting them, letting them know that you are available and always be there to support them. Jonny reacted to his client by quickly altering his emotional display (i.e., expressions) having assumed his client would have been feeling happiness after receiving such an honor. Further, Jonny pushed beyond professional remit to show that he cared for his client on a personal level when they were enduring a difficult situation.

Culture. The different socio-cultural norms of each sport also influenced the emotional labor enactment of SMSs when working with athletes, coaches, performance directors, and SMS staff. Participants were members of, or worked on an ad hoc basis in, varying elite sport organizations across the UK, all of which held divergent histories, values, and aspirations which affected emotional labor enactment. Nuances in culture affected the development of implicit expectations regarding acceptable emotional behaviour, including what emotions to express and avoid, and whether emotions could be spoken about in general.

Emotional display requirements. Participants described unwritten and implicit expectations regarding emotional displays in their respective roles within sport organizations: "I do not think the emotional side is ever discussed, it is always 'behaviour' and what is expected of you." (Lilly). Yet, it was also clear what emotional displays were appropriate and inappropriate. Regarding appropriate emotional displays, Darren, a sport and exercise 
psychologist, summarized the implicit consensus between participants regarding professional demeanor with athletes and coaches and how the emotional state of the client or immediate situation influenced whether and which emotional displays were appropriate.

I am conscious of keeping neutral facial expressions if we are talking about something negative but when there are things you want to reinforce when there are things that people are getting excited about. I feel like if you reflect that back to someone then they buy into your relationship much more because you come across as understanding. Although all participants provided examples of appropriate and inappropriate emotional displays, they also noted that the interpretation of emotional display requirements was subjective and open to contestation with many 'grey areas'. These areas were often problematic requiring a combination of experience and professional judgment to decide the most appropriate course of action. Adam, a male physiotherapist, described a conflict between his professional duties as a physiotherapist and his status as an employee of a football club:

$$
\text { Players trust you with information of a medical nature...You then make a conscious }
$$
decision of whether that affects their performance and if you should share that information with the coaches or the manager. However, quite often players might have trusted you with that information either consciously or subconsciously thinking that you won't pass it on. There's an unwritten rule that you choose what to say and who to say it to... But you soon realize that you can't really be a true physiotherapist in a professional sense and in an ethical and moral sense because you can't be confidential.

Adam was aware that this situation could be perceived as a violation of trust in the practitioner-client relationship, and could evoke a strong emotional response by the athlete. The potential for emotional labor enactment after disclosing private information is concerning and ethically questionable. Therefore, SMSs find themselves attempting to resolve tensions between professional codes of conduct and the cultural and practice norms in sport organizations. 
Sport organization. Interview data also highlighted the unique culture of different sports organizations that permitted certain types of emotional expressions and discouraged others. Zak, a strength and conditioning coach, compared his own experiences in boxing to other sports where the environment affects emotion expressions:

So cycling is very sterile. No emotion, no banter. Just get in, get the job done, get out. Whereas boxing is very loose. It is like rugby, there is a lot of chat, there is a lot of banter, so I think managing one's emotions in the boxing is very easy, well it is always hard to do, but it is less energy consuming than it would be in a sterile environment.

That is, the respective values and attitudes championed by each sport organization influenced the participants' emotional labor enactment. The interview data revealed a sense of ambiguity; it was important to SMSs that the emotions expressed contributed to professional ends, but sometimes those emotional displays might seem unprofessional to others outside the sport. For example, one topic frequently mentioned was the exchange of banter as Darren recollected: In a football club it is called banter, but there are situations that professional football will put you in and things that you might say in those environments, that you would not say when working with other clients. I would love to give you an example but I am fairly certain it is far too inappropriate.

This willingness to be teased was seen to be important to the SMSs' effective functioning, and acceptance by other stakeholders. Nevertheless, SMS were aware of the ambiguity; their professional 'self' might deem the behavior as inappropriate but it was nonethe-less considered to be necessary. Stephen, a sports doctor, remarked that despite his professional level of seniority and responsibility, it was important to engage in banter with athletes and other stakeholders to get to know them and appear approachable.

The practitioner. Participants showed differing interpretations of what appropriate emotional labor enactment constitutes in sports cultures and situations. Throughout the analysis, 
it was apparent that individual differences between practitioners also affected their emotional labor enactment.

Personal characteristics. When asked how they express emotions at work, some SMSs reflected on the personal qualities that influenced how they enacted emotional labor.

Participants felt it necessary to demonstrate emotion abilities such as emotional intelligence to be successful in their role. Lilly, for example, described her ability to read her disgruntled athlete's emotions:

I had a consultation with an athlete on the phone, where that person had not made selection and so their appraisal of that situation is that the coach is useless. I fundamentally disagreed with everything that athlete was saying. Whilst I was listening, I was also internalizing that that person is feeling very emotive, is very frustrated, is very disappointed. The last thing that that person needs is for me to demonstrate that I disagree with them or I am agitated. So you have to. It was completely natural for them to experience a plethora of emotions and totally logical for them to project.

Paul, an experienced strength and conditioning coach, highlighted the responsibility and need to 'read' others to achieve work related goals:

I think we have to be very good at judging personality types and behaviors, and then be able to respond in the right way to get information across, therefore showing the value that we can deliver... Athletes just behave in their way and the expectation is on you to ensure that you manage your behavior to get the best out of them.

For Paul, the ability to judge others' personality, to empathize and be aware of others' emotions was instrumental to achieving effectiveness when practicing.

Experience. A common element affecting emotional labor enactment was the past experiences of participants. The disparity between the challenges of emotional labor when entering the profession for the first time through to years' worth of experience was evident in participant accounts. Reflection on experience was key to developing the skills required to enact 
emotional labor and develop flexibility in the ways SMSs reacted to certain situations (see

Figure 1). As participants became more experienced interacting with stakeholders, the importance of communicating emotions effectively became clear, especially when seeking credibility as a practitioner. For example, the ability to reflect on emotional labor enactment was perceived as critical to the participants' effectiveness as SMSs, as Lilly articulated:

When I think about myself as a person and as a practitioner, I think I could do this job now, I do not think I could have done at the start of my career. Every sport had got its own narrative, its own context, its own rules, and it is quite a unique environment. It is very male dominated, it is very ego driven, and people are not afraid to say what they think. There is a huge emotive aspect to that.

Indeed, for many of the practitioners they perceived experience to develop flexibility in one's approach to emotional labor enactment, as Jim mused when trying to push athletes to the best of their ability:

It's difficult because I don't think there is an easy way of doing [emotional labor]. It's a question of recognizing when you are under pressure and dealing it. Some players you have to have your arm around them, and sometimes you have to be aggressive with them... actually having a mix of that sometimes works quite well.

With increased experience came the confidence to act authoritatively, if required, or affectionately towards athletes without prior concerns about professionalism. Indeed, as indicated in the next theme, emotional labor enactment, it appears that emotional labor perceived as professional depending on the context in which it is performed.

\section{Emotional labor enactment}

Given the influence of many personal and situational factors, the data indicate the interplay between felt emotions, observable emotional expressions, and verbal communication in the emotional labor enactment described by participants. Key issues are a sense of 'acting' out emotions and the 'authenticity' that this might connote. 
Acting. Many participants reported instances where they were required to put on a professional 'act' in front of stakeholders and to moderate their own emotional behavior, this was dubbed the difference between a good SMS and a bad one by Zak, "I think good coaches are like actors in how they can get people to do things. That is just all about being subtle in the way you say things, how you say things, and how your body language is". However, the emotions felt by SMSs were not always congruent with observable and verbal expressions; this surface acting displayed by the participants was characterized as the "professional mask", whereby the SMSs in this study faked emotional expressions needed to appear professional in certain situations. Louise, a sport and exercise psychologist, recalled working with two problematic athletes and the need to conceal her felt emotions:

I masked my emotions literally every day with those girls because they were a nightmare. Not only did I not like their behavior, but I did not like one or two of the individuals at all. I had to cover up my feelings because if I told them what I thought of them that would have been the end of our working relationship and the end of my contract quite frankly... because what I wanted to say was not professional. Situations such as these show the effort and self-control required to suppress or to fake emotional expressions. For Louise, the necessity to act professionally outweighed the need to speak out and highlight poor behavior in this case. Despite the discrepancy between Louise's felt emotions and expressed emotions, the need to be remain positive and to act in a professional manner was prioritized.

In contrast to such surface acting, some SMSs felt it appropriate to perform deep acting, whereby practitioners purposively modified their felt emotions to be in alignment with the expressions that were required in a specific context. Andrew, a strength and conditioning coach, felt arriving ten minutes early to sessions to prepare emotionally gave him the confidence to execute a coaching session to a high standard and led to appropriate emotions being expressed. "Preparation allows you to focus on the parts of the session that are important, and allows you 
to be clear about how you are going to manipulate your emotional state to get the result you want from the athletes." In this case, Andrew made the effort to adjust his felt emotions to be positive or neutral with respect to the feelings of the athlete, leading to emotional congruence, and therefore conveyed authenticity to the athlete. Conveying the professional mask through observable expressions to athletes was critical to professional practice, regardless of the method of acting.

Authenticity. The issues of deep and surface acting are complex and some participants described their need for their internal and external emotions to be congruent, not only for the benefit of stakeholders in sport, but also for themselves. Many SMSs disclosed their awareness of felt emotions in everyday practice and discussed the effortless congruence between felt emotions and emotional expressions in specific situations. Despite this, Andrew reflected that his natural state of authenticity in developing rapport with his athletes could be perceived as problematic by other SMSs:

I have always had friendly engagement with my athletes, whereas I think some practitioners will think you cannot be friends with athletes. I think to deny your own tendencies in relation to something like personal relationships is actually a bit false. I still like to be approachable and friendly in professional relationships, rather than cold and typical.

Andrew was not typical among the participants, and for many the effort associated with the conflict of felt and expressed emotions was troublesome and depleting. Even so, Rory recognized that authentic emotional displays were not always possible when consulting with athletes. As illustrated by the following quotation, he felt emotions become something that are not advisable or helpful to display:

My internal feelings are quite often obvious externally... There are certain circumstances where I control them much better than others, so my natural style is to be very congruent externally and internally... because... to change that... is quite labor 
intensive. In a one-to-one situation with an athlete or a one-to-two situation with a coach and an athlete or even a group educational session, or where I am doing psychology, then I would [conceal emotions]. You would not be able to tell if I was struggling. Ultimately, for Rory and many of the other participants, the most appropriate professional mask for a given situation must be conveyed, regardless of the increased emotional effort and potentially damaging outcomes.

Verbal expressions. In addition to the silent and observable emotional expressions characterized by "the professional mask" many participants recalled that verbalizing emotions often resulted in avoidable conflict. Ash spoke about how the type of emotions communicated impacted upon others' personal and professional opinions of him as a physiotherapist:

I think you learn quickly not to show yourself up and you learn which individuals you can and can't say certain things to. You've got to be prepared for the backlash, because sometimes [honest, but negative] things do need saying.

Clive, a physiotherapist, struggled to understand the injury of an introverted athlete and used positive emotive communication to help the athlete. This way, he created an environment whereby the athlete could talk about the things on his mind:

My strategy with the introvert who is not very responsive is to ensure that once a week we have quiet time, where he is free to say anything. It's because our sessions are 100 miles an hour otherwise, where I lead a rather clinical meeting. I say, "you're the boss, you're doing the rehab and you tell me what you feel.

According to Clive, one result of this emotive communication was athletes 'opening up in a safe environment'. The subsequent information revealed by athletes allowed Clive to better treat the injury and progress their recovery with an enhanced working relationship.

\section{Professional and personal outcomes}

Throughout the analysis, outcomes associated with emotional labor enactment were evident in SMSs responses. Participants described how emotional labor enactment was used as 
a professional tool to achieve work goals, which had professional and personal effects on the practitioner. SMSs highlighted the unique pressures associated with the requirement to persuade athletes to undertake certain interventions.

Professional outcomes. When discussing the outcomes of their emotional labor participants emphasized their professional priority to enhance sports performance and engage in positive, transformational work with athletes. The data indicate that work leading up to performance improvements is inherently emotional, and requires SMSs to manipulate their emotional expressions to achieve optimal performance environments and working relationships. The analysis indicates that trust and relationship management are important outcomes of emotional labor for SMSs.

Buy in. Many participants discussed enacting emotional labor to persuade an athlete to cooperate and engage in beneficial activities that would aid their performance. Louise spoke about 'selling the value of sports psychology' to athletes to promote engagement by managing her emotions:

It's all about impression management and selling sports psychology. We know goal setting works from the evidence base but if you're not selling goal setting and this person doesn't trust you, then it is not going to work with them.

Zak echoed this sentiment and found managing his emotions critical to reaching goals with his athletes:

I think unless you can control [your emotions] it is game over because at the end of the day you need that athlete to buy in to what you are doing. You are trying to get them to do something that they may not like, the only way you are going to do that is if you get buy in. It is always about finding what works for that individual and trying to get the emotion across to their level to get the outcome that you want.

Professional relationships. The emotional labor outcomes manifested in professional relationships with clients was indicated-by all the participants as an important part of athlete 
career improvement. However, negotiating and navigating professional boundaries is complex as no "professional" relationship described was the same and decisions made by the SMS, and the emotions displayed in the practitioner to athlete context was significant for the efficacy of those relationships. Louise stated, "You cannot build a relationship and you cannot build trust without demonstrating appropriate emotions". Louise also reflected that:

I think [emotion management] is really important because the way you say things, the way you conduct yourself, the way you manage your reactions to what they may say, influences their whole experience of you... So, you manage your emotions to manage how a person experiences you, that is influencing the relationship. It is the way you sit, the way you react, the way you listen, the eye contact you give, the way you use humor, put people at ease... it all involves emotions and trying to influence someone, not in a manipulative way, but in a way that will help them.

Through emotional labor enactment, therefore, SMSs developed rapport and trust, which became the foundation of fruitful professional working relationships and provided the basis for positive athlete engagement.

Positive emotional contagion. A further outcome of emotional labor, linked with issues of surface and deep acting that participants highlighted relates to the priority of developing positive emotions that increase athlete engagement with the SMS. The data indicate that the interviewees regarded negative emotional displays as unhelpful and unprofessional; the needs of the athlete outweighed personally felt emotions in the workplace. Ryan discussed displaying positive emotions visually and verbally to increase the output of athletes in his sessions: If you are not showing a great deal of enthusiasm for a session that you think is quite important, why should you expect your athletes to not mirror that? The level of emotion I push in my description is going to be something that really gets them engaged.

Personal outcomes. Although participants were clear about the needs of the athlete they also reported personal detriments associated with their emotional labor and the personal 
consequences of strains between surface acting and the challenges of achieving professional goals and athlete performance outcomes. This study highlights that there is no right or wrong way of approaching emotional labor when working as a professional SMS. However, inexperience, a lack of reflection on past experiences, or a misjudgment about professional distance had a profound and detrimental personal effect on SMSs. The data indicate the personal and professional pressures of using emotional labor to achieve professional impression management and the struggle to negotiate a balance of personal and professional demands and identity as an SMS.

Responsibility. Participants in the present study often reported the emotionally charged feeling of personal responsibility when athletes were not performing to the best of their ability. Ash recalled, "You feel very responsible sometimes, like it's actually your fault. It's that 'Oh God...' you know? You're feeling responsible for it and you're feeling bad for the player." Louise questioned her own professional effectiveness and publicly devalued herself on a professional and personal basis when athletes suffered defeat:

I have a role to ensure that they achieve and performed optimally when it mattered which is at this event, they weren't. So it wasn't necessarily the moment of emotion regulation that affected me, I mean it was effortful, but I did it so I was proud of myself. It was actually my reflection of 'how have we got to this point? What was my role? What was my failure?' So I actually took it really hard that they had under-performed so significantly. It made me think that I wasn't as good as I thought I was.

Personal impact. The data also suggest complexities associated with emotional labor outcomes; emotional labor to develop relationships with athletes can be significantly positive for professional effectiveness but it also poses a risk should the relationship be suddenly ended. Lilly worked with an athlete over many years, and when this athlete was at a competition in Australia, they became seriously ill, which had knock on effects for the SMS: 
He was given a less than $5 \%$ chance of survival. So you have supported an athlete for prolonged period of time, you have worked with them every week for two or three years, and then you get a call to say, 'I need to let you know, that this person is not likely to survive.' His parents had also received the call who would have then had to have got onto a flight to Australia and would not know whether their child would be dead or alive when they got to the other end. You can't be unaffected by those things. You cannot walk into your house at the end of the day with a smile on your face.

The profound impact of situations such as these can have significant implications for SMSs operating in emotionally demanding environments and some SMSs reflected on their own health outcomes as a result.

Mental health issues. The balance between enacting emotional labor and being successful over a prolonged period was reported by SMSs to lead to mental health issues, as illustrated by Jonny's quotation:

I think sometimes in managing the demands of work, and the emotional aspects of the work and trying to be successful, my personal life has suffered. So I was effective in what I was doing at work, but it took its toll. And I think sometimes the nature of sport is influential, the unsociable hours, the unpredictability of it, it can be all-consuming, and therefore you look like you are coping with it, and you are, but you are using so much of your resources in trying to cope with it.

Lauren made similar comments regarding the demands of SMSs in high performance sport having implications for her mental health:

Often, because you feel quite isolated you tend to internalize things. I've got a few little strategies that might help with coping with things like that. But often you don't have an outlet and you've got to be professional all the time.

\section{Discussion}


The three overarching themes illustrated how emotional labor impacts SMSs professional practice: (a) factors affecting emotional labor enactment, (b) emotional labor enactment, and (c) professional and personal outcomes. The analysis provides the basis for a model of emotional labor in sports medicine and science (see Figure 1) that emphasizes the importance of experience and reflection for becoming aware of and enacting emotional labor in elite sport organizations. The personal accounts of sports medics, physiotherapists, sport and exercise psychologists, and strength and conditioning coaches underline the value of the findings for a range of audiences, not least: prospective SMSs; those responsible for managing SMS and performance departments in sport organizations; human resources departments in charge of recruiting and retaining talent, and; professional bodies and institutions responsible for educating, training, and developing SMSs for employment in elite sport.

Personal and situational characteristics of SMSs are important influences on emotional labor which seems to be a pragmatic issue of emotional control that practitioners in this study needed to deploy when faced with various situations and displays of intense emotions by athletes. As Figure 1 illustrates, emotional labor is developed as a form of tacit knowledge to meet the emotional demands of elite sport. Onthe-job experience and the ability to reflect on that experience as a practitioner in the field are important influences on developing capacity for emotional labor enactment. Those practitioners who had been in the elite sport context for longer were often better equipped to deal with emotional labor demands, yet unpredictable and previously unencountered situations influenced their engagement and affected their ability to manage. These findings are also apparent in studies of professions such as teaching (Zembylas, 2007) and nursing (Herbig, Büssing \& Ewert, 2001) which indicate that experience and a reflective awareness of emotional knowledge is important when dealing with critical situations. To some extent it might be expected that, due to the nature of psychological practice, that 
sport and exercise psychologists in this study would face numerous and diverse emotionladen transactions with their clients (principally athletes), some of which fell outside of their professional remit (e.g., clinical mental health issues). Nevertheless, physiotherapists and strength and conditioning coaches also reported similar situations, despite limited professional training for the management of such situations or their emotional fallout. Emotional display requirements were largely influenced by the norms of the sport to an extent (Wagstaff et al., 2012), but these data also show the influence of practitioners' personalities, personal philosophies, and self-awareness.

The findings presented here also indicate the relevance of concepts established in the literature (cf. Grandey \& Gabriel, 2015); this study provides further evidence of enactment methods of emotional labor (i.e., surface acting, deep acting, and authentic emotional expression). In the case of elite sport, however, participants described their emotions as inherently inter-subjective (i.e., influenced by interactions with others) and performative (i.e., purposefully adjusting observable emotional expressions) in the elite sport socio-cultural context (Tamminen et al., 2017). Indeed, the results of this study indicate that it is reasonable to expect that SMSs, in common with other professional groups such as medical, legal and academic practitioners (Day \& Leitch, 2001; Herbig et al., 2001; Anleu \& Mack, 2005) will perform a combination of surface acting, deep acting, and authentic emotional expression on any given day via a combination of visual, verbal, and non-verbal communication that conveys professionalism. In response to the array of influential factors on emotional labor enactment, SMSs were aware of the need to wear a "professional mask" and control their emotional reactions. If the appropriate emotions were put across to the athletes in their unique contexts, and were perceived as honest and authentic to athletes, this led to fruitful consequences for professional practice.

Figure 1 also identifies outcomes pertaining to the consequences of emotional labor for professional practice in SMS. Participants reported emotional labor to be 
beneficial to professional practice, but potentially negative in its personal affect.

Unreflective behavior was also considered to be detrimental to professional practice.

Specifically, the results contribute further evidence about the personal (e.g., mental health issues; Lee et al., 2016) and the professional (e.g., turnover intention or being ousted from a role; Larner et al., 2017) ramifications associated with emotional labor. Despite their awareness of the potentially negative personal implications for practitioners, the participants in this study reported a perceived need to convey the professional emotions to achieve work goals regardless of the method of, or personal cost of, its enactment.

A significant contribution from this study is that the achievement of optimal workrelated outcomes (i.e., improving athlete performance) was more important than the personal impact of surface or deep acting for SMSs. Given the potentially negative consequences of emotional labor demands, findings such as this highlight the need for governing bodies (e.g., CSP, BPS, British Association of Sport and Exercise Medicine) and elite sport organizations to review their range of services to SMSs to raise awareness about the emotional requirements associated with this form of work and the potential effects on practitioner welfare. Further studies into the effects of emotional labor demands on SMS's mental health are also necessary. Such investigations could lead to the design and provision of adequate social support systems (e.g., communities of coping and counselling; Korczynski, 2003) for SMSs when dealing with sensitive issues or difficult life periods, and mitigate professional competency issues before they come into fruition.

\section{Applied implications}

Three implications for SMS professional practice arise from the salient competency requirement for emotional labor in the SMS professions. First, emotional labor formed a necessary part of practice in all SMS roles sampled, yet it is currently not evident in ethical codes of conduct and professional practice guidelines (e.g., Health Care and Professions Council) and from policy debates in elite sport organizations. This 
warrants further attention by these bodies. Second, these findings indicate that an education-training-practice gap exists in SMS with regards to the emotional labor requirements of professional practice. It may be that neophyte practitioners are unaware of the need to enact emotional labor to stakeholders and in differing situations, or the reasons as to why they may enact emotional labor. Previous research has shown the usefulness and effectiveness of reflective practice in sport and performance psychology (Devonport \& Lane, 2014), sports physiotherapy (Hollingworth, Dugdill \& Prenton, 2014) and sports coaching (Peel, Cropley, Hanton \& Fleming, 2013). Third, Figure 1 indicates the priority of encouraging reflective practice to understand the intersection between emotional labor and practical skills throughout taught education, training and continuing professional development initiatives to enables practitioners to personally and professionally benefit from reflecting on experiences (their own and that of others) of emotional labor.

These results and our interpretation of them indicate several avenues for further research. Specifically, given the pragmatic use of emotional labor dependent on the situation (i.e., event characteristics), and individual differences contingent to the practitioner (i.e., person characteristics) reported here, we encourage practitioners to provide their own in-depth ethnographic accounts to illustrate their personal experiences of emotional labor (e.g., factors influencing emotional labor, emotional labor enactment, professional and personal outcomes). For example, original accounts by practitioners in sport professions would provide meaningful, more personalized understandings of the manifestations of emotional labor and the effects it may have on professional practice. Further, exploration of emotional labor requirements at differing levels of communication (i.e., practitioner to client, practitioner to group, within practitioner groups) would further elucidate the emotional demands faced by practitioners who provide services to a range of stakeholders in sport organizations. 
Two principal limitations of this study are acknowledged. First, the inclusion criteria for this study and the snowball sampling strategy led to the recruitment of a sample that is predominantly male. This is aligned with the current male domination of SMS professions; European Union statistics indicate fewer women working in sport (43\%) compared to men (57\%) in the UK (Eurostat, 2015) and gender inequality has been identified in sport and exercise medicine (Bekker et al., 2016), strength and conditioning coaching (Magnusen \& Rhea, 2009), and sports psychology (Lovell, Parker, Brady, Cotterill \& Howatson, 2011). Therefore, the study findings might not represent the potentially gendered emotional labor required by females in male dominated environments and this represents an area where further research is required. Second, a combination of face-to-face, telephone, and computer mediated interviewing (i.e., Skype) was used to interview participants and this diversity brings with it a limitation (Hanna, 2014) as visual cues and a volume of contextual and nonverbal data were not available from non-face to face interactions (Sparkes \& Smith, 2014).

\section{Perspectives}

This study provides a novel exploration of the emotional labor experiences of SMS practitioners operating in elite sport in the UK. It shows that emotional labor enactment is critical to professional effectiveness, despite potentially negative personal outcomes. The consistent perceived necessity of emotional labor enactment in SMS professional practice raises the question as to whether emotional labor should be considered a professional competency and thus included in education and training. These findings should inform policy and practice in sport organizations (e.g., national sport organizations), Higher Education Institutions involved with training prospective SMSs, professional bodies involved with the training and development of SMSs (e.g., BASES, BPS, CPS), and professional practice bodies in charge of producing ethical codes of conduct and regulating such professions (e.g., Health Care and Professions Council). 


\section{References}

Anderson AG, Knowles Z, Gilbourne D. Reflective practice for sport psychologists: concepts, models, practical implications, and thoughts on dissemination. Sport Psychol 2004: 18: 188-203.

Anleu SR, Mack K. (2005). Magistrates' everyday work and emotional labour. J Law Soc 2005: 32: $590-614$.

Bekker S, Blake T. The Eva Carneiro case and gender inequality in SEM: Why it matters for the SEM community. Br J Sports Med Blog, 2016: Retrieved from http://blogs.bmj.com/bjsm/2016/07/08/the-eva-carneiro-case-and-gender-inequality-insem-why-it-matters-for-the-sem-community/

Braun V, Clarke V, Weate P. Using thematic analysis in sport and exercise research. In: Smith B, Sparkes AC, eds. Routledge Handbook of Qualitative Research in Sport and Exercise. UK: Routledge., 2016: 191-205.

Burke S. Rethinking 'validity' and 'trustworthiness' in qualitative inquiry: How we might judge the quality of qualitative research in sport and exercise sciences? In Smith B, \& Sparkes AC. Eds. Routledge Handbook of Qualitative Research in Sport and Exercise. UK: Routledge: 2016: 330-339.

Cassidy T. The role of theory, interpretation and critical thought within qualitative sport and exercise research. In Smith B, \& Sparkes AC. Eds. Routledge Handbook of Qualitative Research in Sport and Exercise. UK: Routledge: 2016: 397-408.

Devonport TJ, Lane AM. The utility of reflective practice during the provision of sport psychology support. In: Knowles Z, Gilbourne D, Cropley B, Dugdill L. eds. Reflective Practice in the Sport and Exercise Sciences: Contemporary Issues. UK: Routledge., 2014: 160-168.

Day C, Leitch R. Teachers' and teacher educators' lives: The role of emotion. Teach Teach Educ 2001: 17: 403-415. 
1 Eurostat. Employment in sport. 2015: Retrieved from http://ec.europa.eu/eurostat/statisticsexplained/index.php/Employment_in_sport\#Methodology_.2F_Metadata

Foster C, Sayers J. Exploring physiotherapists' emotion work in private practice. N Z J Physiother 2012: 40: 17-23.

Gallmeier CP. Putting on the game face: the staging of emotions in professional hockey. Sociol Sport J 1987: 4: 347-362.

Galvan ZJ, Ward P. Effects of public posting on inappropriate on-court behaviors by collegiate tennis players. Sport Psychol 1998: 12: 419-426. Organization, 2003: 10: 55-79. 
Larner RJ, Wagstaff CRD, Thelwell RC, Corbett J. A multistudy examination of organizational stressors, emotional labor, burnout, and turnover in sport organizations. Scand J Med Sci Sports 2017: 00: 1-13.

Lee YH, Chelladurai P. Affectivity, emotional labor, emotional exhaustion, and emotional intelligence in coaching. J Appl Sport Psychol 2016: 28: 170-184.

Lee YH, Chelladurai P, \& Kim Y. (2015). Emotional labor in sports coaching: development of a model. Int J Sports Sci Coach 2015: 10: 561-575.

Lovell GP, Parker JK, Brady A, Cotterill ST, Howatson G. Looking the part: Female sports psychologists' body mass index and dress influences athletes' perceptions of their potential effectiveness. Sport Psychol 2011: 25: 82-93.

Magnusen MJ, Rhea DJ. Division I athletes' attitudes toward and preferences for male and female strength and conditioning coaches. Journal of Strength \& Conditioning Coach Research 2009: 23: 1084-1090.

Manley AJ, Greenlees IA, Thelwell RC, Filby WCD, Smith MJ. Athletes' perceived use of information sources when forming initial impressions and expectancies of a coach: an explorative study. Sport Psychol 2008: 22: 73-89.

Nelson L, Allanson A, Potrac P, Gale L, Gilbourne D, Marshall P. Thinking, feeling, acting: the case of a semi-professional soccer coach. Sociol Sport J 2013: 30: 467-486.

Peel J. Cropley B, Hanton S, Fleming S. Learning through reflection: values, conflicts, and role interactions of youth sport coach. Reflective Practice 2013: 14: 729-742.

Reid C, Stewart E, Thorne G. Multidisciplinary sport science teams in elite sport: comprehensive servicing or conflict and confusion? Sport Psychol 2004: 18: 204-217.

Ryba TV, Haapenen S, Mosek S, Ng K. (2012). Towards a conceptual understanding of acute cultural adaptation: A preliminary examination of ACA in female swimming. Qualitative Research in Sport, Exercise and Health 2012: 4: 80-97. 
Smith B, McGannon KR. Developing rigor in qualitative research: Problems and opportunities within sport and exercise psychology. Int Rev Sport Exerc Psychol 2017: 1-21.

Sparkes AC, Smith B. Qualitative Research Methods in Sport, Exercise and Health. UK: Routledge., 2014: 83-114.

Tamminen KA, Bennett EV. No emotion is an island: An overview of theoretical perspectives and narrative research on emotions in sport and physical activity. Qualitative Research in Sport, Exercise and Health 2017: 9: 183-199.

Tamminen KA, Crocker PRE. "I control my own emotions for the sake of the team": Emotional self-regulation and interpersonal emotion regulation among female high-performance curlers. Psychol Sport Exerc 2013: 14: 737-747.

Thelwell RC, Wagstaff, CRD, Rayner A, Chapman M, Barker J. Exploring athletes' perceptions of coach stress in elite sport environments. J Sport Sci 2017: 35: 44-55.

Tod D, Marchant D, Andersen MB. Learning experiences contributing to service-delivery competence. Sport Psychol 2007: 21: 317-334.

Tonn E, Harmison RJ. Thrown to the wolves: a student's account of her practicum experience. Sport Psychol 2004: 18: 324-340.

Wagstaff CRD, Fletcher D, Hanton S. Exploring emotion abilities and regulation strategies in sport organizations. Sport Exerc Perform Psychol 2012: 1: 268-282.

Wagstaff CRD, Gilmore S, Thelwell RC. Sport medicine and sport science practitioners' experiences of organizational change. Scand J Med Sci Sports 2015: 25: 685-698.

Zembylas M. Emotional ecology: The intersection of emotion knowledge and pedagogical content knowledge in teaching. Teach Teach Educ 2007: 23: 355-367. 
1 Table 1. Participant demographic information.

\begin{tabular}{|c|c|c|c|c|}
\hline $\begin{array}{c}\text { Participant } \\
\text { (pseudonym) }\end{array}$ & Gender & Professional Role & $\begin{array}{l}\text { Qualifications/ } \\
\text { Accreditation }\end{array}$ & $\begin{array}{l}\text { Practitioner } \\
\text { experience }\end{array}$ \\
\hline Louise & Female & $\begin{array}{l}\text { Sport and exercise } \\
\text { psychologist }\end{array}$ & $\begin{array}{c}\text { BSc, MSc, PhD/ } \\
\text { BPS, BASES } \\
\text { (psychology - } \\
\text { scientific support) }\end{array}$ & $16-20$ years \\
\hline Ash & Male & Physiotherapist & $\begin{array}{c}\text { BSc, PGCert/HCPC, } \\
\text { CSP }\end{array}$ & $0-5$ years \\
\hline $\mathrm{Jim}$ & Male & Physiotherapist & $\begin{array}{c}\text { BSc, Dip, } \\
\text { MSc/HCPC, CSP } \\
\text { FSMM }\end{array}$ & $20+$ years \\
\hline Roger & Male & $\begin{array}{l}\text { Sport and exercise } \\
\text { psychologist }\end{array}$ & $\begin{array}{c}\text { BSc, MSc, PhD/ } \\
\text { BPS, HCPC, BASES } \\
\text { (psychology - } \\
\text { scientific support) }\end{array}$ & $11-15$ years \\
\hline Jonny & Male & $\begin{array}{l}\text { Sport and exercise } \\
\text { psychologist }\end{array}$ & $\begin{array}{c}\mathrm{BSc}, \mathrm{PhD} / \mathrm{BPS}, \\
\mathrm{HCPC}\end{array}$ & $20+$ years \\
\hline Darren & Male & $\begin{array}{l}\text { Sport and exercise } \\
\text { psychologist }\end{array}$ & $\begin{array}{c}\mathrm{BSc}, \mathrm{MSc} / \mathrm{BPS}, \\
\text { HCPC }\end{array}$ & $6-10$ years \\
\hline Lauren & Female & Physiotherapist & $\begin{array}{c}\text { BSc, MSc, } \\
\text { PGCert/HCPC, } \\
\text { ACPSEM, CSP }\end{array}$ & $11-15$ years \\
\hline Lilly & Female & $\begin{array}{l}\text { Sport and exercise } \\
\text { psychologist }\end{array}$ & $\begin{array}{c}\text { BSc, MSc, PhD/ } \\
\text { BPS, HCPC }\end{array}$ & $11-15$ years \\
\hline Andrew & Male & $\begin{array}{c}\text { Strength and } \\
\text { conditioning coach }\end{array}$ & $\mathrm{BSc}, \mathrm{MSc} / \mathrm{UKSCA}$ & $16-20$ years \\
\hline Zak & Male & $\begin{array}{c}\text { Strength and } \\
\text { conditioning coach }\end{array}$ & $\mathrm{BSc}, \mathrm{MSc} / \mathrm{UKSCA}$ & $6-10$ years \\
\hline Ryan & Male & $\begin{array}{c}\text { Strength and } \\
\text { conditioning coach }\end{array}$ & $\mathrm{BSc}, \mathrm{MSc} / \mathrm{UKSCA}$ & $11-15$ years \\
\hline Frank & Male & Sports scientist & BA, MA & $0-5$ years \\
\hline David & Male & $\begin{array}{c}\text { Strength and } \\
\text { conditioning coach }\end{array}$ & $\begin{array}{c}\text { BSc, MSc/ UKSCA, } \\
\text { BASES (sport and } \\
\text { exercise scientist) }\end{array}$ & $6-10$ years \\
\hline Paul & Male & $\begin{array}{c}\text { Strength and } \\
\text { conditioning coach }\end{array}$ & $\mathrm{BSc}, \mathrm{MSc} / \mathrm{UKSCA}$ & $11-15$ years \\
\hline Stephen & Male & Sports Doctor & $\mathrm{MD}, \mathrm{MSc}$ & $11-15$ years \\
\hline Rory & Male & $\begin{array}{l}\text { Sport and exercise } \\
\text { psychologist }\end{array}$ & $\begin{array}{l}\text { BSc, MSc, BSc, } \\
\text { MSc, PhD/BASES } \\
\text { (psychology - } \\
\text { scientific support), } \\
\text { BPS, HCPC }\end{array}$ & $11-20$ years \\
\hline Adam & Male & Physiotherapist & $\begin{array}{c}\text { BSc, MSc, } \\
\text { PGCert/CSP, HCPC }\end{array}$ & $11-15$ years \\
\hline Clive & Male & Physiotherapist & $\mathrm{BSc} / \mathrm{CSP}, \mathrm{HCPC}$ & $16-20$ years \\
\hline
\end{tabular}


1 Figure 1: Emotional labor and professional practice in sports medicine and science

2 practitioners.

3

4

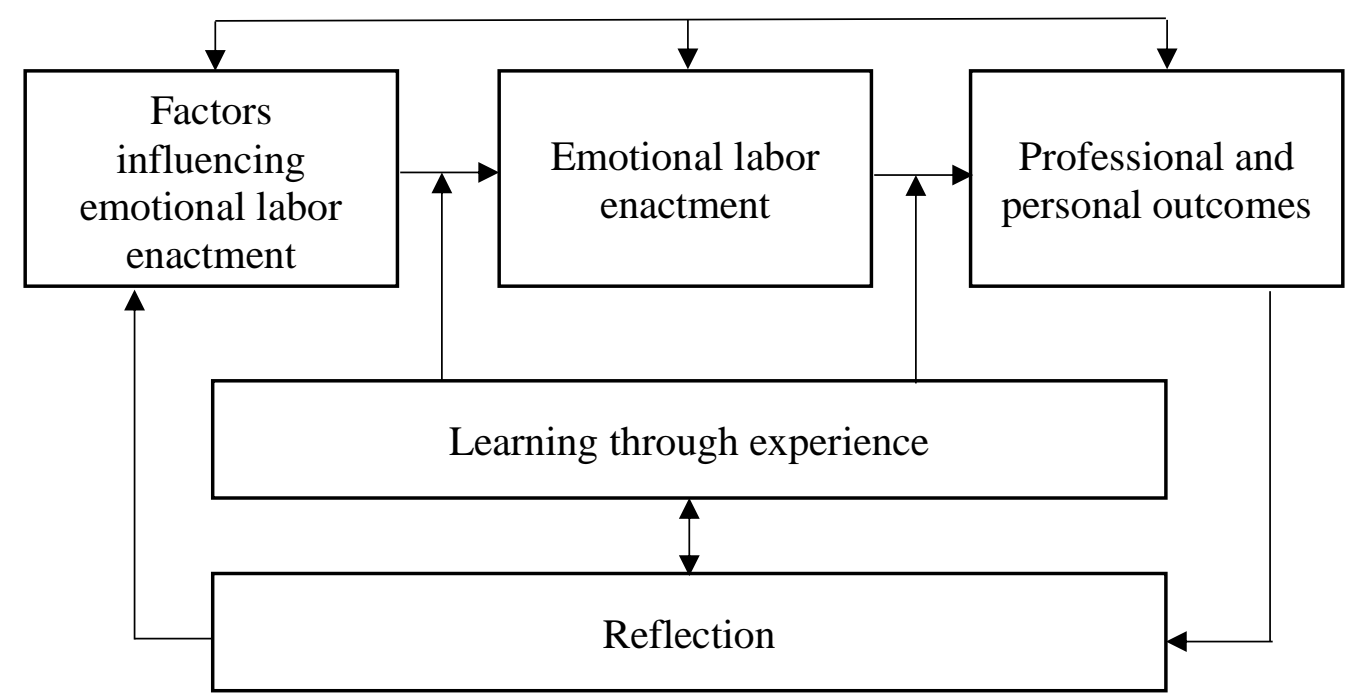

11 